\title{
Characterization of Cellulose Nitrate by Thin-Layer Chromatography
}

\author{
Kenji Kamide, ${ }^{*}$ Tetsuro OKada, ${ }^{* *}$ Toshikazu TeraKawa, ${ }^{*}$ \\ and Katsumasa KANEKO** \\ *Textile Research Laboratory, Asahi Chemical Industry Company, Ltd., \\ Takatsuki, Osaka 569, Japan. \\ **Department of Industrial Chemistry, Faculty of Technology, \\ Kanazawa University, Kotatsuno 2, Kanazawa 920, Japan.
}

(Received January 12, 1978)

\begin{abstract}
The intent of this work is to establish a method for evaluating the chemical compositional distribution (CCD, in this case, nitrogen content $(N c)$ ) and the molecular weight distribution (MWD) of cellulose nitrate (CN) using open and vapor-programed (VP) thin-layer chromatography (TLC). CCD could be determined with a nitromethane-methanol mixture in open TLC and with acetone-methanol-chloroform in VP-TLC. With mainly the former, the change in the rate of flow $R_{\mathrm{f}}$ was based on the adsorption-desorption mechanism and with the latter, the separation of polymer according to $N c$ was interpreted by the phase separation mechanism. Both methods gave similar CCD for given $\mathrm{CN}$ samples. The most effective method for evaluating the weight-average molecular weight was achieved with 1,4-dioxane-methanol-isopropanol mixture in VP-TLC, for which the phase separation mechanism was operative.
\end{abstract}

KEY WORDS Cellulose Nitrate / Thin-Layer Chromatography / Compositional Distribution / Molecular Weight Distribution / AdsorptionDesorption Mechanism / Phase Separation Mechanism /

Since its first appearance in 1831, cellulose nitrate (hereafter designated as $\mathrm{CN}$ ) has occupied, in spite of rapid growth of the production of synthetic polymers, invariably an important position in industry owing to its numerous favorable features. As is well-known, $\mathrm{CN}$ is commercially utilized by changing it's average molecular weight and the average degree of esterification (i.e., the nitrogen content by wt $\%$ as expressed by $N c$ ). A number of attempts have been made to separate whole $\mathrm{CN}$ polymer with respect to molecular weight or $N c$. But, unfortunately no effective method of compositional fractionation has yet been proposed for CN. In 1973 Kamide, et al., ${ }^{1}$ succeeded, by using thin-layer chromatography (TLC), to evaluate molecular weight distribution (MWD) and chemical compositional distribution (CCD) of cellulose acetate. Quite recently, Kamiyama and Inagaki ${ }^{2}$ studied by TLC the compositional heterogeneity of some commercial $\mathrm{CN}$ samples by a concentration-gradient development using a binary acetone-ethylacetate $(20 / 3, v / v)$ and another binary chloroformethylacetate $(1 / 2, v / v)$ as initial and second solvents, respectively. However, they have not established a method for estimating MWD or CCD of $\mathrm{CN}$ by TLC technique. This work intends to fractionate $\mathrm{CN}$ on the basis of $N c$ or its molecular weight by TLC.

\section{EXPERIMENTAL}

\section{Preparation of Polymer Samples}

Eleven whole samples have been used in this work. These samples were prepared by nitrating purified cotton linter with a mixture of nitric acid and sulfuric acid, followed by a conventional thermal degradation at elevated temperatures in water. The sample W 119 was fractionated, by successive solutional fractionation (SSF) technique, into five fractions at $25^{\circ} \mathrm{C}$ from a $0.8-w t \%$ solution in acetone using hexane as a precipitant. 


\section{K. Kamide, T. OKada, T. Terakawa, and K. Kaneko}

Among these fractions thus isolated, the fifth fraction (coded as S19-5) was employed for further study.

The viscosity-average molecular weight $\bar{M}_{\mathrm{v}}$ was calculated from limiting viscosity number [ $\eta$ ] data in acetone at $25^{\circ} \mathrm{C}$ using the following Mark-Houwink-Sakurada relation ${ }^{3}$ :

$$
[\gamma]=2.53 \cdot 10^{-2} \bar{M}_{\mathrm{n}}{ }^{0.795} \quad\left([\eta]: \mathrm{cm}^{3} / \mathrm{g}\right)
$$

which has been originally established for the cellulose nitrate fractions with $N c=12.2 \mathrm{wt} \%$. The value of $\bar{M}_{\mathrm{v}}$ is listed in the last column of Table I. $N c$ was determined by micro-Duma's method $^{4}$ with a micro determining apparatus for nitrogen type MU-2 (Yanagimoto Seisakusho, Japan) and recorded in the third column of Table I.

Table I. Characteristics of cellulose nitrate samples

\begin{tabular}{lcccc}
\hline $\begin{array}{c}\text { Sample } \\
\text { code }\end{array}$ & $\begin{array}{c}\text { Fraction } \\
\text { or whole } \\
\text { polymer }\end{array}$ & $\begin{array}{c}\text { Nitrogen } \\
\text { content, } \\
(N c), \text { wt } \%\end{array}$ & $\begin{array}{c}{[\eta] \text { in }} \\
\text { acetone } \\
25^{\circ} \mathrm{C}, \\
\mathrm{cm}^{3} / \mathrm{g}\end{array}$ & $\bar{M}_{\mathrm{v}} \times 10^{-4^{\mathrm{a}}}$ \\
\hline HIG 1/2 & $\mathrm{W}^{\mathrm{b}}$ & 11.9 & 65.4 & 1.96 \\
HIG 2 & W & 11.8 & 87.5 & 2.82 \\
HIG 7 & W & 11.7 & 127 & 4.51 \\
HIG 20 & W & 11.8 & 156 & 5.85 \\
HIG 80 & W & 11.9 & 212 & 8.60 \\
HIG 120 & W & 11.8 & 240 & 10.0 \\
HIG 1000 & W & 12.1 & 370 & 17.3 \\
W 115 & W & 11.5 & 431 & 21.0 \\
W 119 & W & 11.9 & 436 & 21.3 \\
W 121 & W & 12.1 & 512 & 26.0 \\
W 127 & W & 12.7 & 531 & 27.3 \\
S19-5 & F & 11.7 & 831 & 47.9 \\
\hline
\end{tabular}

a $\bar{M}_{\mathrm{v}}$ was determined from $[\eta]$ by use of eq 1 .

b Whole polymer.

c Fraction.

\section{Preparation of Thin-Layer}

Silica gel (trade name Kieselgel G nach Stahl, type 60 , manufactured by E. Merck, Darmstadt, W. Germany), aluminum oxide (trade name aluminum oxide $\mathrm{G}$, type $60 / \mathrm{E}$ by Merck) and Kieselguhr (trade name Kieselguhr G, Merck) in powder form were used as the substrate for TLC. A slury composed of two parts water and one part adsorbent (by weight) was spread evenly on a glass plate, thoroughly washed, by a conventional applicator (Automatic TLC-coater with adsorbent hopper manufactured by Camag, Switzerland). The plate was air-dried at room temperature for $15 \mathrm{~min}$ and was activated for $1 \mathrm{hr}$ in an oven at $110^{\circ} \mathrm{C}$, immediately before use. It was then cooled to room temprature and preserved in a desiccator. The tickness of the adsorbent layer was adjusted to $0.25 \mathrm{~mm}$.

\section{TLC Experiment}

All solvents employed were of guaranteed grade and to remove any trace of impurities were mixed with granular active carbon which was subsequently filtered with porous polymeric membrane with an average pore size of $0.1 \mu \mathrm{m}$, distilled under reduced pressure, when necessary.

$\mathrm{CN}$ samples were dissolved in acetone at a concentration of $0.76 \mathrm{wt} \%$. The solution thus prepared was dropped, with the aid of a microsyringe, onto the plate $1.5 \mathrm{~cm}$ away from the lower edge of the plate so as to make a spot $5 \mathrm{~mm}$ in diameter. Each spot on the layer was formed by a $42-\mu \mathrm{g} \mathrm{CN}$ polymer.

In this study, two kinds of TLC experiments (open and VP-TLC) were carried out: In the open TLC experiment, the TLC plate was placed in a rectangular box with an open end as a development vessel and the polymer sample was developed by the natural ascending method. In this case, the development was performed in an unsaturated vapor phase. A high reproducibility was attained by carefully controlling the atomosphere surrounding in a development vessel. This technique has been first successfully applied to the separation of cellulose acetate. ${ }^{1}$ When a closed development vessel was employed in place of the box chamber with an open end (i.e., conventional TLC), no efficient separation occurred under the same operating conditions (developer, stationary phase and developing method) as those used in open TLC. VP-TLC is a very precise kind of gradient elution. Its experimental procedure has been briefly described by Zeeuw, ${ }^{5}$ and was utilized with modification in this study. A vapor-programming chamber (Vario-KS chamber manufactured by Camag, Switzerland) was used. With this chamber we could accurately control the vapor pressure during the development on any portion of the plate. The cross sectional view of the chamber is illustrated in Figure 1.

Each subdivision in the trough chamber was 


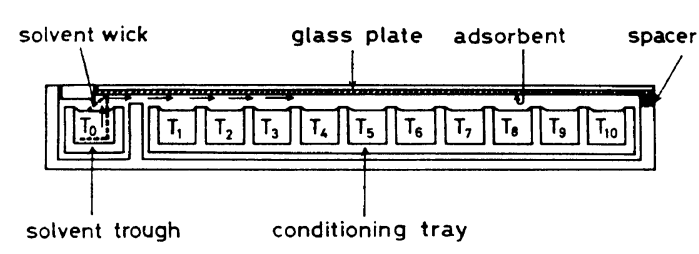

Figure 1. Cross-sectional view of the chamber for vapor-programming (VP)-TLC.

filled with a different solvent mixture having a given composition before development, and was carefully determined by preliminary experiment to bring about the best separation. On the basis of our experience, we strongly recommend for continuous gradients, if the phase-separation mechanism is predominantly operative in the TLC, that the concentration of good solvents (for example, chloroform in the compositional fractionation (Figure 9) and 1,4-dioxane in the molecular weight fractionation (Figure 12)) in a subdivision is decreased (accordingly, that of poor solvents is increased) as the distance of the subdivision from the starting points is increased (i.e., $T_{1}-T_{10}$ ). The solvent mixture as developer was then poured into the solvent trough. In this experiment, a shaped paper spacer frame of 0.2 $\mathrm{cm}$ thickness was inserted between the cleared rim of the TLC plate and the corresponding ridge of the conditioning tray so that the continuous vaporphase gradient along the direction of development could be built up. Without this kind of spacer, transverse bands were frequently observed in the carbonized chromatograms, corresponding to the distance of the walls of the subdivisions in the tray.

The glass plate with the polymer samples loaded and the thin-layer facing downwards, was pressed horizontally on the vapor-programming chamber. Prior to the chromatographic development, the TLC layer was allowed to stand for $20 \mathrm{~min}$ in order to absorb vapor molecules evaporating from the conditioning trays. Then, the $\mathrm{CN}$ samples on the starting point were developed with solvents which transferred through the solvent wick, made of filter paper from the solvent trough.

The development was stopped when the solvent front reached $10 \mathrm{~cm}$ above the original point of samples (i.e., the starting point). After the run was completed, the plate was dried by blowing air at room temperature. To visualize physically polymers on the plate, the thin-layer plate was sprayed with $10-w t \%$ aqueous sulfuric acid fumes; then the polymer on the layer was carbonized by heating at $110^{\circ} \mathrm{C}$ in an electric oven. The sensitivity of detecting the polymers spread on the plate was $0.1-\mu \mathrm{g} \mathrm{CN} / \mathrm{mm}$. The profiles were recorded in a Shimadzu dual-wave length TLC scaner at a wave length, $\lambda$ of $380 \mathrm{~nm}$. In this case, a zigzag scanning method was employed (beam $1.25 \mathrm{~mm} \times 1.25 \mathrm{~mm}$, width of swing stroke 30 $\mathrm{mm}$ ). Although the spots of chromatogram have a very complicated form as was illustrated in Figure 3, the intensity curve has a single-peak or at most is doubly-peaked. The weight-average value of $R_{\mathrm{f}}\left(R_{\mathrm{f}, \mathrm{w}}\right)$ was calculated from the intensity curve.

The phase ratio defined by the weight of solvent (mobile phase), retained by a unit weight of thinlayer (stationary phase), was determined by the difference between the weight of gel layer, containing the solvent, for the area arbitrarily scraped off and that of the gel dried.

The change in composition of the solvent as a function of the distance from the starting points, was determined by the Shimadzu gas chromatograph model GC-4CMPF which has a flameionization detector.

\section{RESULTS AND DISCUSSION}

\section{Compositional Fractionation}

In the preliminary experiment, six samples HIG 1/2, HIG 80, HIG 100, W 115, W 121, and W 127 were subjected to TLC development with single solvents such as nitromethane, methanol, acetone, methylethylketone, ethanol, acetic acid, tetrahydrofuran, ethylacetate, 1,4-dioxane, $n$-butanol, isopropanol, dichloromethane, toluene, $n$-hexane, benzene, and chloroform. In this case, three stationary phase types, (i.e., silica gel, aluminum oxide and kieselguhr) and the natural ascending methods, were employed for open TLC. The first nine solvents behaved as good solvents for $\mathrm{CN}$ but the remainder (seven solvents) were poor. The $R_{\mathrm{f}}$ value had no correlation to the dielectric constant $\varepsilon$ of the solvent. Without exception good solvents migrated the $\mathrm{CN}$ samples. Especially, tetrahydrofuran and 1,4-dioxane gave $R_{\mathrm{f}}=1$ for 
all samples examined, but when poor solvents were used as developing agents, all the $\mathrm{CN}$ samples remained on the starting line. This suggests that the most important factor of the solvent suitable for TLC experiment is that the solvent can dissolve the polymer sample to be examined, as was described by Inagaki for adsorption TLC. ${ }^{2}$ The elution of $\mathrm{CN}$ with a single solvent was not successful, since neither the average molecular weight dependence nor the degree of substitution dependence of $R_{\mathrm{f}, \mathrm{w}}$ were observed in the case of single solvent development.

Next, we tested the binary mixtures at various compositions, arbitrarily chosen from solvents mentioned above, in order to fractionate $\mathrm{CN}$ according to the chemical composition (i.e., $N c$ ). As a consequence, the system of nitromethane and methanol gave a satisfactory chemical fractionation by the open TLC technique. Both nitromethane and methanol are good solvents with high dielectric constant $\varepsilon=35.87$ and 32.63 , respectively.

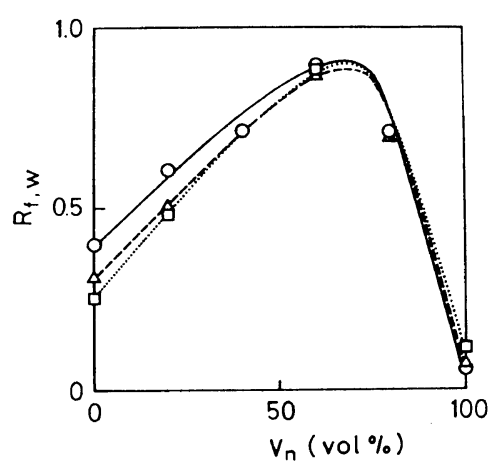

Figure 2. Dependence of $R_{\mathrm{f} \text {, w }}$ for cellulose nitrate on volume percent of nitromethane, $v_{\mathrm{n}}$ : $\mathrm{O}, \mathrm{W} 115$ $(N c=11.5 \mathrm{wt} \%) ; \quad \triangle$ W $121 \quad(N c=12.1 \mathrm{wt} \%) ; \quad \square$, W $127(N c=12.7 \mathrm{wt} \%) . \quad R_{\mathrm{f}}$ was determined on silica gel with nitromethane-methanol mixture (open TLC).

Figure 2 shows the variation of $R_{\mathrm{f}, \mathrm{w}}$ value obtained for three $\mathrm{CN}$ samples (W 115, W 121 and $\mathrm{W} 127)$ having different $N c(N c=11.5 \mathrm{wt} \%$ (full line), $12.1 \mathrm{wt} \%$ (broken line) and $12.7 \mathrm{wt} \%$ (dotted line)), with changing composition of the developer system of nitromethane and methanol. $R_{\mathrm{f}, \mathrm{w}}$ passes through a maximum at a point of a nitromethane content $\left(v_{\mathrm{n}}\right.$ in $\left.\mathrm{vol} \%\right)$ of $70 \%$. In other words, the dependence of $R_{\mathrm{f}}$ on the nitrogen content of the samples changes its sign at this point. The maximum $R_{\mathrm{f} \text {, w }}$ value remains almost constant, and independent of $N c$. Similar $R_{\mathrm{f}, \mathrm{w}}-v_{\mathrm{n}}$ relations have been reported for isotactic poly(methyl methacrylate) fraction in a chloroform - methanol system ${ }^{6}$ and cellulose acetate fraction in a methylene chloride- $n$-butanol system. ${ }^{1}$ Clearly, there exists a composition (in this case, $v_{\mathrm{n}}=0 \sim 40 \mathrm{vol} \%$ ), at which the CCD evaluation can be performed most effectively. However, if the phenomenon of the downward tailing of the spot is taken into account, $v_{\mathrm{n}}=20 \sim 40 \mathrm{vol} \%$ is much more desirable. Hereafter, the system of nitromethane and methanol $\left(20 / 80, \mathrm{v} / \mathrm{v}\right.$ at $\left.25^{\circ} \mathrm{C}\right)$ was used to fractionate $\mathrm{CN}$ samples with regard to $N c$ by open TLC. Methanol is well-known for its displacing action.

$$
\underset{\substack{\text { Solvent } \\ \text { front }}}{\longrightarrow}
$$

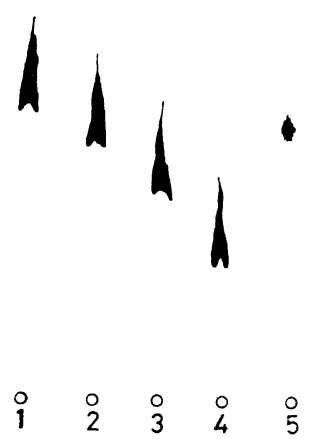

Figure 3. TLC chromatograms obtained for cellulose nitrate samples having a different nitrogen content and almost the same molecular weight: silica gel, nitromethane-methanol (open TLC); 1, W 115; 2, W $119 ; 3$, W $121 ; 4$, W 127; 5, S19-5.

Figure 3 shows a separation of five different $N c$ samples. Evidently, all the samples except for a fraction S19-5 are developed as very complicated bands. The $R_{\mathrm{f}}$ value decreases with increasing $N c$ and varies by a factor of more than two over a $N c$ range from 11.5 to $12.7 \mathrm{wt} \%$.

Figure 4 illustrates the limiting viscosity number [ $\eta$ ] of samples W 115 and W 127 in mixtures of 


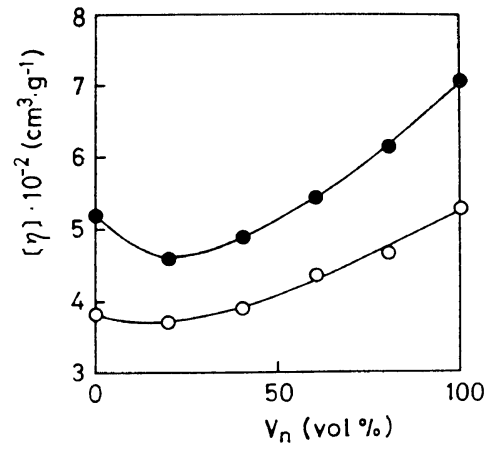

Figure 4. Plot of limiting viscosity number $[\eta]$ at $25^{\circ} \mathrm{C}$ against the composition of nitromethanemethanol mixture, expressed by nitromethane content $\left(\operatorname{vol}_{\%}^{\circ}\right) v_{\mathrm{n}}$ : O, W $115(N c=11.5 \mathrm{wt} \%) ; \mathrm{O}, \mathrm{W} 127$ $(N c=12.7 \mathrm{wt} \%)$.

nitromethane and methanol. The $[\eta]$ of both samples exhibits a minimum when the composition of nitromethane-methanol is $20 / 80\left(\mathrm{v} / \mathrm{v}\right.$ at $\left.25^{\circ} \mathrm{C}\right)$. That is to say, at this composition, being most effective for compositional separation, the polymer molecules exist in the most contracted form. It was confirmed by the measurement of the phase ratio as a function of the position on layer that the polymer molecules do not precipitate over the entire range of the composition of solvent mixture examined, indicating that the separation according to the chemical composition by open TLC with nitromethane-methanol mixture is based not on the phase-separation mechanism, but probably on

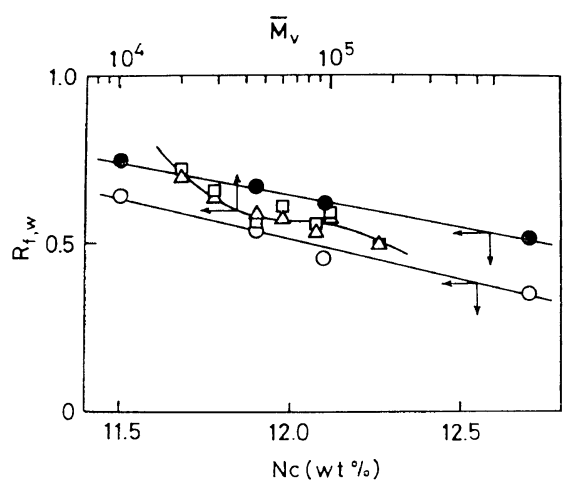

Figure 5. Dependence of $R_{\mathrm{f}, \mathrm{w}}$ on nitrogen content $(\mathrm{Nc})$ and on the viscosity-average molecular weight $\bar{M}_{\mathrm{v}}$ : open TLC, nitromethane-methanol, 20/80, $\mathrm{v} / \mathrm{v}$; open mark; silica gel; closed mark, alumina; $\square$, first run; $\triangle$, second run. the adsorption-desorption mechanism.

Figure 5 shows the dependence of $R_{\mathrm{f}, \mathrm{w}}$ on $N c$ for $\mathrm{CN}$ samples with similar $\bar{M}_{\mathrm{v}}(21 \sim 27 \cdot 10)^{4}$ as open circle (silica gel) or closed circle (aluminum oxide), which are eluted with constant composition of mixed solvent (nitromethane-methanol $\left(20 / 80, v / v\right.$ at $\left.25^{\circ} \mathrm{C}\right)$ in open TLC. CN with higher $N c$ exhibits a lower $R_{\mathrm{f}, \mathrm{w}}$ value than polymer with lower $N c$. The following relations are obtained by the least-square method:

$$
R_{\mathrm{f}, \mathrm{w}}=3.43-0.244 N c(\mathrm{wt} \%) \text { : silica gel }
$$

$11.5 \leq N c($ wt $\%) \leq 12.7$

and

$R_{\mathrm{f}, \mathrm{w}}=2.95-0.192 N c(\mathrm{wt} \%):$ aluminum oxide $(3)$

$$
11.5 \leq N c(\text { wt } \%) \leq 12.7
$$

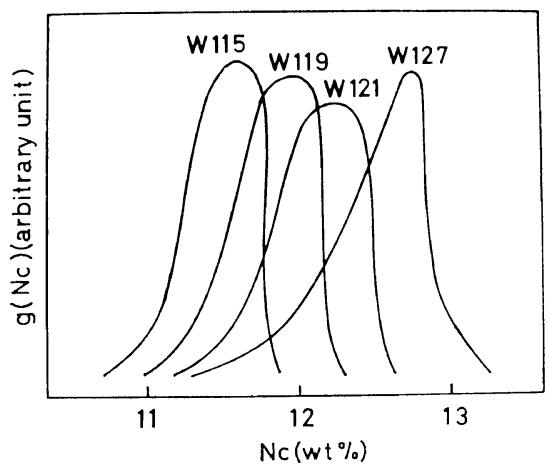

Figure 6. Differential weight distribution of nitrogen content $(N c$ by wt $\%) g(N c)$ for several cellulose nitrate samples evaluated by open TLC (silica gel, nitromethane-methanol, 20/80, v/v).

Figure 6 shows the differential weight distribution(s) of nitrogen content, $g(N c)$, converted by the relationship between linearized absorbance of carbonized chromatogram (incident beam $\lambda=$ $380 \mathrm{~nm}$ ) and the $R_{\mathrm{f}}$ for various $\mathrm{CN}$ samples with different $N c$. The preliminary experiments confirmed a reasonable proportionality between the absorbance of the carbinized chromatogram and the amount of $\mathrm{CN}$ developed on the chromatogram, independent of the nitrogen content, at least over the entire experimentally accessible range. Inagaki, et al., ${ }^{7}$ observed for poly(methyl methacylate) that the above relations vary markedly according to the configuration of the polymer, 
due to the large difference in affinity of the iodine molecules used for visualizing a chromatographic spot for poly(methyl methacrylate). The absorbance is proportional to the differential weight distribution $g(N c)$.

The absolute value of $R_{\mathrm{f}, \mathrm{w}}$ is larger in the case of aluminum oxide used as stationary phase, than for silica gel. This suggests that silica gel has, at least as far as this experiment is concerned, a larger absorbing power than aluminum oxide. The accuracy in evaluating $N c$, expressed by $\mathrm{d} R_{\mathrm{f}, \mathrm{w}} / \mathrm{d} N c$, seems dependent on the adsorbent nature. The polymer samples having different $\bar{M}_{\mathrm{v}}$ and almost the same $N c(=11.8 \mathrm{wt} \%)$ were chromatogramed under the same conditions as those employed for the open circle in Figure 5. These results are also shown in Figure 5 as an open triangle (first run) and an open rectagle (second run). $R_{\mathrm{f}, \mathrm{w}}$ can be regarded as approximately constant within an $\bar{M}_{\mathrm{v}}$ range of $4 \times 10^{4} \sim$ $15 \times 10^{4}$ and in this limited range, $N c$ can be accurately determined from $R_{\mathrm{f}, \mathrm{w}}$ value independent of the average molecular weight by open TLC technique (nitromethane-methanol). But in the range, $\bar{M}_{\mathrm{v}}<4 \cdot 10^{4}$ and $\bar{M}_{\mathrm{v}}>1.5 \times 10^{5}, R_{\mathrm{f}, \mathrm{w}}$

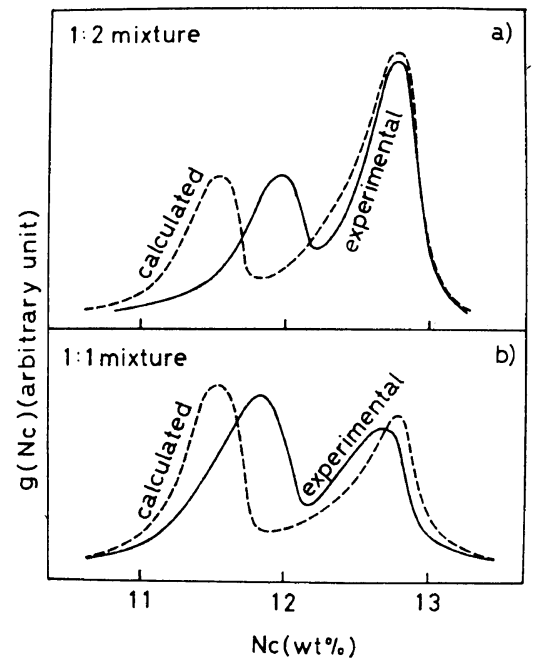

Figure 7. Experimental and calculated weight distribution curves of nitrogen content $(N c), g(N c)$, for 1: 2 and 1:1 (by weight) mixtures of samples W 127 and W 115: full line, experimental curve; broken line, line calculated from experimental chromatogram of each component, nitromethane-methanol, 20/80, $\mathrm{v} / \mathrm{v}$ at $25^{\circ} \mathrm{C}$, open TLC. depends appreciably on both $N c$ and $\bar{M}_{\mathrm{v}}$.

Figure 7 shows the experimental and calculated weight distribution curves of $N c, g(N c)$, for $1: 2$ and 1: 1 (by weight) mixtures of samples W 115 and $\mathrm{W} 127$. The experimental curves were obtained from chromatograms for the 1:2 and 1:1 (by weight) mixtures of samples W 127 and W 115 developed under the following conditions: nitromethane-methanol $(20 / 80, v / v)$, natural ascending method, silica gel, open TLC. The broken lines were calculated on the basis of chromatograms for samples W 115 and W 127, developed under the same conditions as those for the mixtures. The mixtures are separated into two upper and lower spots overlapped slighly at intermediate region. It is very important to notice that the experimental curve is a fairly good reflection of the CCD curve, although $N c$ of the lower $N c$ components is slightly overestimated.

The VP-TLC technique was applied for $\mathrm{CN}$ samples with the nitromethane-methanol $(20 / 80$, $\mathrm{v} / \mathrm{v})$ system. The $R_{\mathrm{f}} v s$. $N c$ plot obtained from their chromatograms is graphed as an open mark in Figure 8, where silica gel (triangle) as well as the kieselguhr (circle) were employed as the stationary phase. Included in the figure are the results by open TLC as a closed mark for comparison. The following relations are evaluated for VP-TLC:

$$
\begin{array}{r}
R_{\mathrm{f}, \mathrm{w}}=1.82-0.119 N c(\mathrm{wt} \%) \quad: \\
\text { silica gel at } 25^{\circ} \mathrm{C} \\
11.5 \leq N c(\mathrm{wt} \%) \leq 12.7
\end{array}
$$

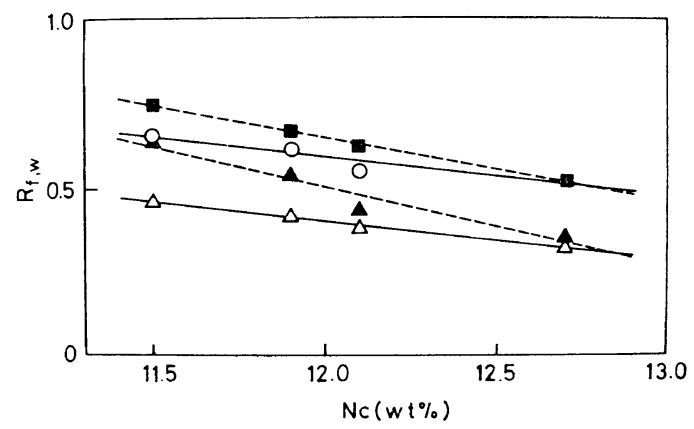

Figure 8. Dependence of $R_{\mathrm{f}, \mathrm{w}}$ for cellulose nitrate on nitrogen content $(N c)$ : nitromethane-methanol, 20/80, v/v; $\boldsymbol{\Delta}$, open TLC, silica gel; $\mathbf{v}$, open TLC, alumina; $\triangle$, VP-TLC silica gel; $O$, VP-TLC, kieselyuhr. 
Characterization of Cellulose Nitrate by Thin-Layer Chromatography

$$
\begin{gathered}
R_{\mathrm{f}, \mathrm{w}}=2.04-0.121 N c(\mathrm{wt} \%): \\
\text { kieselguhr at } 25^{\circ} \mathrm{C} \\
11.5 \leq N c(\mathrm{wt} \%) \leq 12.7
\end{gathered}
$$

Obviously, the separation efficiency is much better in open TLC than in VP-TLC, if the nitromethane-methanol system is employed as the developer. Thus, other solvent mixtures were surveyed in order to improve the efficiency of $N c$ evaluation by VP-TLC.

A good separation of the $\mathrm{CN}$ polymer with compositional heterogeneity was achieved with a $10 / 10 / 5\left(\mathrm{v} / \mathrm{v} / \mathrm{v}, 25^{\circ} \mathrm{C}\right)$ acetone-methanol-chloroform mixed solvent elution by the VP-TLC technique (stationary phase $=$ kieselguhr). The first two solvents are good solvents for $\mathrm{CN}$ and have high dielectric constant $(\varepsilon=20.7$ for acetone and 32.6 for methanol), but the last solvent is nonsolvent for $\mathrm{CN}$ and has a low dielectric constant $(\varepsilon=4.62)$. Figure 9 illustrates the $N c$ dependence of $R_{\mathrm{f}, \mathrm{w}}$ for four samples W 115, W 119, W 121, and $\mathrm{W} 127$, obtained under the above conditions. The results for 20/80 (v/v) nitromethane-methanol mixture by VP-TLC are also plotted in the figure using the triangle. From Figure 9 we obtain

$$
\begin{array}{r}
R_{\mathrm{f}, \mathrm{w}}=3.78-0.275 N c(\mathrm{wt} \%) \quad: \\
\text { silica gel at } 25^{\circ} \mathrm{C} \\
11.5 \leq N c(\mathrm{wt} \%) \leq 12.7
\end{array}
$$

and

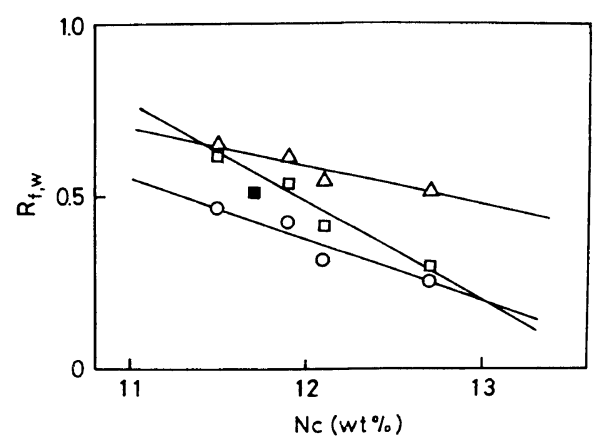

Figure 9. Dependence of $R_{\mathrm{f}, \mathrm{w}}$ for cellulose nitrate samples on nitrogen content $(N c)$ (VP-TLC): $O$, kieselguhr, acetone-methanol-chloroform (10/10/5, $\mathrm{v} / \mathrm{v} / \mathrm{v}$, at $\left.25^{\circ} \mathrm{C}\right) ; \square, \mathbf{D}$, silica gel, acetone-methanolchloroform $\left(10 / 10 / 5, \mathrm{v} / \mathrm{v} / \mathrm{v}\right.$, at $\left.25^{\circ} \mathrm{C}\right) ; \triangle$, kieselguhr, nitromethane-methanol $\left(20 / 80, \mathrm{v} / \mathrm{v}\right.$, at $\left.25^{\circ} \mathrm{C}\right)$, VPTLC; open mark, whole polymer; closed mark, fraction.

$$
\begin{aligned}
& R_{\mathrm{f}, \mathrm{w}}=2.59-0.184 N c(\mathrm{wt} \%) \quad: \\
& \text { kieselghur at } 25^{\circ} \mathrm{C} \\
& 11.5 \leq N c(\mathrm{wt} \%) \leq 12.7
\end{aligned}
$$

Equation 6 should be compared with eq 4; eq 7 corresponds to eq 5 . In the case of VP-TLC with acetone-methanol-chloroform (silica gel), the $R_{\mathrm{f}, \mathrm{w}}$ value of the fraction $\mathrm{S} 19-5$ deviates slightly from the value expected from eq 6 . This should be understood due to the large difference in the average molecular weight between the fraction and the whole polymers.

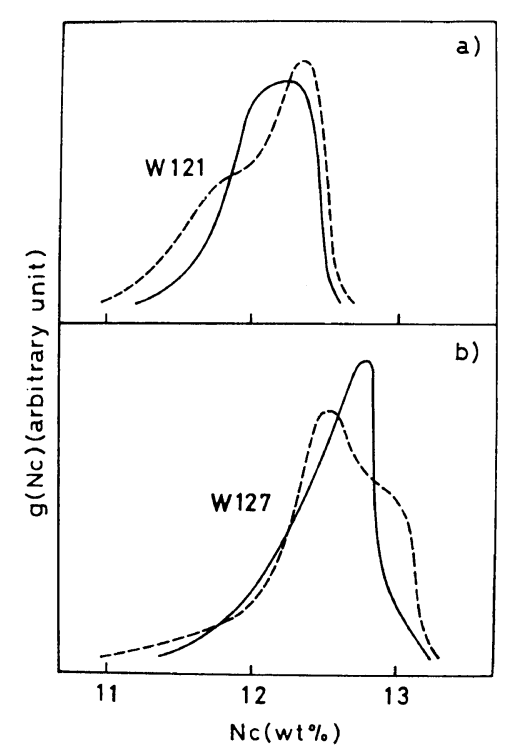

Figure 10. Differential weight distribution of nitrogen content ( $N c$ by wt \%) $g(N c)$ of W 121 and W 127 estimated by TLC: full line, silica gel, open TLC, nitromethane-methanol $(20 / 80, v / v)$; broken line, kieselguhr, VP-TLC, acetone-methanol-chloroform $(10 / 10 / 5, \mathrm{v} / \mathrm{v} / \mathrm{v})$.

Figure 10 shows the differential weight distribution of $N c, g(N c)$ for the two samples W 121 and W 127 estimated by two TLC techniques. A full line is obtained by open TLC with nitromethane-methanol $(20 / 80, \mathrm{v} / \mathrm{v})$ mixture (silica gel) and a broken line means VP-TLC with acetone-methanol-chloroform (10/10/5, v/v/v). The agreement between the $g(N c)$ curves evaluated by both methods is good, considering the chance for large experimental uncertainity.

Figure 11 is a graph of the compositional varia- 


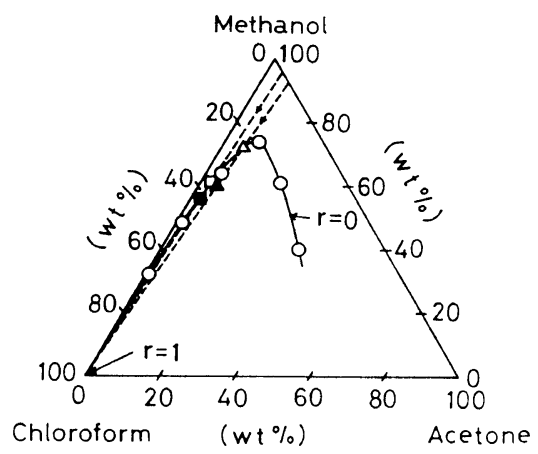

Figure 11. Variation of the composition of solvent mixtures in the development of VP-TLC: open mark, experimental data point; open triangle, $R_{\mathrm{f}}$ for sample W 127 ; open rectangle; $R_{\mathrm{f}}$ for sample W 115 ; closed triangle, precipitating point for sample W $115 ; r$, see text.

tion of solvent mixtures on the layer in the development process of VP-TLC. The open mark means the experimental data points. In this figure, $r$ is the ratio of $Z$ to $Z_{\mathrm{f}}$, where $Z$ is the distance of an arbitarily chosen point from the starting point and $Z_{\mathrm{f}}$ is the distance of the end point from the starting point (in this case, $Z_{\mathrm{f}}=$ $10 \mathrm{~cm}$ ). At the initial stage, with an increase in $r$, the methanol content increases, passes through a maximum, and finally decreases to zero at $r=1.0$, where the developer consists only of chloroform. The open triangle is the solvent composition at the $R_{\mathrm{f}, \mathrm{w}}$ value of sample W 127 ; the open rectangle corresponds to the $R_{\mathrm{f}, \mathrm{w}}$ value of sample W 115. From a knowledge of the phase ratio and the weight of the polymer deposited, the polymer concentration was found to be $0.34 \mathrm{~g} / 100 \mathrm{~g}$ solvent mixture for W 127 and $0.33 \mathrm{~g} / 100 \mathrm{~g}$ solvent mixture for $\mathrm{W} 115$. Solutions of the samples W 127 and W 115 in mixtures of acetone and methanol were prepared under the same conditions (weight ratio of polymer-acetone-methanol) as those of the open triangle and the open rectangle. Chloroform was added dropwisely to the solutions thus prepared and the composition of each solution, at which it becomes turbid, was determined and is shown as closed marks in Figure 11. The solvent mixture at $R_{\mathrm{f}}$ of $\mathrm{CN}$ samples can be considered to be roughly equal to that at the precipitating point. In other words, the fractionation with respect to $N c$ by these solvent mixtures (VP-TLC) is explain- ed in terms of the polymer phase-separation mechanism.

\section{Molecular Weight Fractionation}

In a preliminary expreiment, the combination of 1,4-dioxane-methanol-2-propanol mixture (15/ $10 / 1, \mathrm{v} / \mathrm{v} / \mathrm{v}$ ) as the developer and kieselghur as the stationary phase in VP-TLC proved successful for molecular weight fractionation.

Figure 12 shows photometric recording curves of blackness of the chromatographic bands ob-

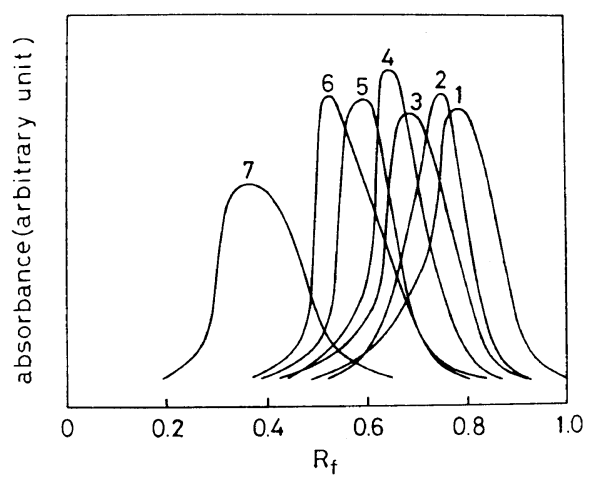

Figure 12. TLC chromatograms obtained for cellulose nitrate samples having different $\bar{M}_{\mathrm{v}}$ and the same $N c$, kieselguhr, 1,4-dioxane-methanol-2-propanol $\left(15 / 10 / 1, \mathrm{v} / \mathrm{v} / \mathrm{v}\right.$ at $\left.25^{\circ} \mathrm{C}\right)$, VP-TLC: $1, \mathrm{HIG} 1 / 2 ; 2$, HIG 2; 3, HIG 7; 4, HIG 20; 5, HIG 80; 6, HIG 120; 7, HIG 1000.

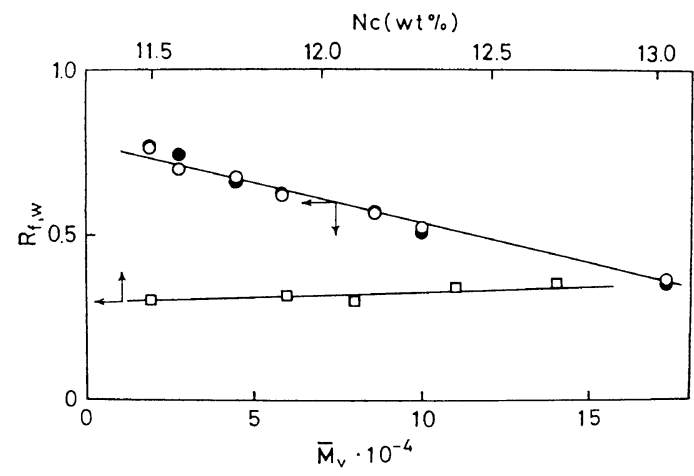

Figure 13. Molecular weight dependence of $R_{\mathrm{f}, \mathrm{w}}$ for cellulose nitrate samples having the same $(N c=$ $11.8 \mathrm{wt} \%$ ) (circle) and nitrogen content $(N c)$ dependence of $R_{\mathrm{f}, \mathrm{w}}$ for cellulose nitrate samples having almost the same $\bar{M}_{\mathrm{v}}$ and different $N c$ (rectangular): kieselguhr, 1,4-dioxane-methanol-2-propanol (15/ $10 / 1, \mathrm{v} / \mathrm{v} / \mathrm{v}$ at $25^{\circ} \mathrm{C}$ ). 
tained under the above conditions for seven $\mathrm{CN}$ samples with the same $N c(11.8 \mathrm{wt} \%)$ and different $\bar{M}_{\mathrm{v}}$. Chromatograms shift to small $R_{\mathrm{f}}$ region as $\bar{M}_{\mathrm{v}}$ increases.

Figure 13 displays the molecular weight dependence of $R_{\mathrm{f}, \mathrm{w}}$, evaluated from Figure 12. In this figure, open and closed circles mean the first and second runs, respectively. From Figure 13 we obtain:

$$
\begin{aligned}
R_{\mathrm{f}, \mathrm{w}}=0.792-2.50 \cdot 10^{-6} \bar{M}_{\mathrm{v}}: \\
1.96 \leq \bar{M}_{\mathrm{v}} \cdot 10^{-4} \leq 17.3 \\
N c=11.8 \mathrm{wt} \%, \text { kieselghur }
\end{aligned}
$$

Under the same operating conditions as employed for establishing eq 8 , the chromatograms for the polymer samples with similar $\bar{M}_{\mathrm{v}}\left(21 \times 10^{4} \sim 27.3 \times\right.$ $10^{4}$ ) and the different $N c$ were obtained. The results are also shown as a rectangle in Figure 13. Evidently, $R_{\mathrm{f}, \mathrm{w}}$ depends only slightly on $N c$, according to the relation:

$$
\begin{aligned}
& R_{\mathrm{f}, \mathrm{w}}=-0.205+ 0.044 N c \quad: \\
& 11.5 \leq N c(\mathrm{wt} \%) \leq 12.9 \\
& \bar{M}_{\mathrm{v}}=21 \sim 27.3 \cdot 10^{4}
\end{aligned}
$$

Strictly speaking, it is impossible to fractionate $\mathrm{CN}$ samples according to molecular weight without incurring interference from the difference in chemical constitution. But, from a practical point of view, the $R_{\mathrm{f}}$ value can be considered independent of the difference in $N c$.

Figure 14 shows the compositional variation of solvent mixtures (1,4-dioxane-methanol-isopro-

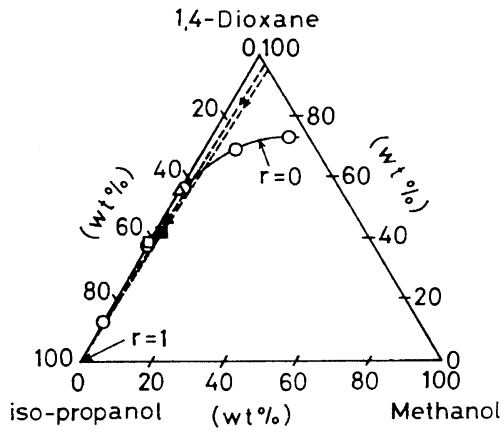

Figure 14. Variation in the composition of solvent mixture (1,4-dioxane, methanol, isopropanol) in the development of VP-TLC. All symbols are the same as those in Figure 11. panol) on the layer. As $r$ increases, the methanol content decreases gradually and the dioxane content decreases drastically, both approaching zero at $r=1.0$. Although the difference between the solvent composition at the $R_{\mathrm{f}}$ value for polymer sample $\mathrm{W} 121$ and that at the precipitating point is not negligibly small, we can consider, as a first approximation, that the molecular weight fractionation by VP-TLC of 1,4-dioxane-methanol-2-propanol is governed mainly by the phaseseparation mechanism.

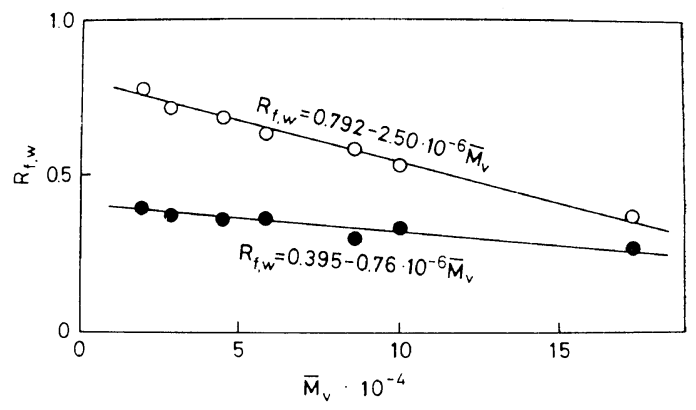

Figure 15. Influence of substrate on $R_{\mathrm{f}, \mathrm{w}}$ vs. $\bar{M}_{\mathrm{v}}$ relations for cellulose nitrate $(N c=11.8 \mathrm{wt} \%)$ : VPTLC, 1,4-dioxane-methanol-2-propanol (15/10/1, $\mathrm{v} / \mathrm{v} / \mathrm{v}$ at $\left.25^{\circ} \mathrm{C}\right) ; \mathrm{O}$, kieselguhr; $\bullet$, silica gel.

Figure 15 demonstrates the influence of the substrate on $R_{\mathrm{f}, \mathrm{w}} v s$. the $\bar{M}_{\mathrm{v}}$ relations for $\mathrm{CN}$ samples $(N c=11.8 \mathrm{wt} \%)$. Data points were obtained by VP-TLC in 1,4-dioxane-methanolisopropanol mixture $\left(15 / 10 / 1, \mathrm{v} / \mathrm{v} / \mathrm{v}\right.$ at $\left.25^{\circ} \mathrm{C}\right)$. The open mark in the figure is the results in Figure 13. For silica gel we obtain:

$$
R_{\mathrm{f}, \mathrm{w}}=0.395-0.76 \cdot 10^{-6} \bar{M}_{\mathrm{V}}
$$

$1.96 \leq \bar{M}_{\mathrm{v}} \times 10^{-4} \leq 17.3, N c=11.8 \mathrm{wt} \%$, silica gel The adsorbing power is stronger in silica gel than in kieselghur and the latter is evidently much more effective.

Provided that the chromatograms obtained under the above conditions represent the true molecular weight distribution of the polymer, we calculated the weight-average molecular weight $\bar{M}_{\mathrm{w}}$ from chromatograms (see, Figure 12). The relationships between $\bar{M}_{\mathrm{w}}$ thus determined and $\bar{M}_{\mathrm{v}}$ are plotted in Figure 16. The $\bar{M}_{\mathrm{w}}$ by TLC $\simeq$ $\bar{M}_{\mathrm{v}}$ was obtained over the molecular weight range investigated. 


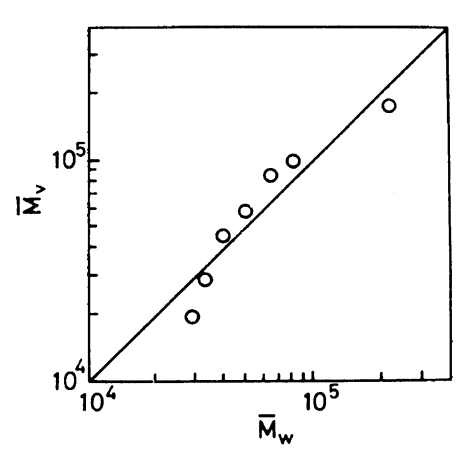

Figure 16. Relationship between the viscosity-average molecular weight $\bar{M}_{\mathrm{v}}$ and the weight-average molecular weight $\bar{M}_{\mathrm{w}}$, as determined by VP-TLC (1,4-dioxane-methanol-2-propanol, 15/10/1, v/v/v at $25^{\circ} \mathrm{C}$, kieselguhr).

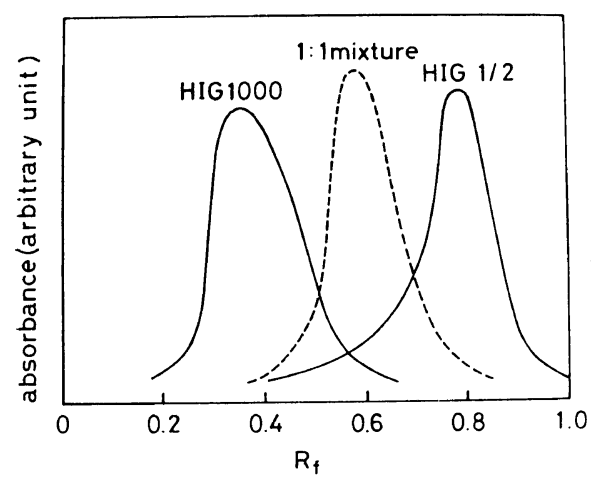

F'gure 17. TLC chromatograms obtained for cellulose nitrate samples having different $\bar{M}_{\mathbf{v}}$ (HIG $1 / 2$ and HIG 1000) and their 1: 1 (by weight) mixture: kieselguhr, 1,4-dioxane-methanol-2-propanol, 15/ $10 / 1, \mathrm{v} / \mathrm{v} / \mathrm{v}$ at $25^{\circ} \mathrm{C}$ ).

It should be noted, however, that the obtained chromatograms do not always represent the true molecular weight distribution of the samples.
This is illustrated in Figure 17, where chromatograms of the two polymer samples as well as their 1: 1 (by weight) mixture are shown. Surprisingly, the chromatogram of the $1: 1$ mixture shows only a spot lying just between their components. Similar results were obtained with various twocomponent mixtures. At the present time we cannot explain this unexpected phenomenon explicitly. The apparent molecular weight evaluated from these chromatogram $\bar{M}_{\mathrm{w}}$ (by TLC) is not far from the $\bar{M}_{\text {w }}$ calculated.

Acknowledgment. The authors would like to express their gratitude to Prof. S. Ishida of Kanazawa University and Drs. S. Manabe and Y. Miyazaki of the Textile Research Laboratory, Asahi Chemical Industry Company, Ltd. for their stimulating remarks.

\section{REFERENCES}

1. K. Kamide, S. Manabe, and E. Osafune, Makromol. Chem., 168, 173 (1973).

2. H. Inagaki, Thin layer chromatography in "Fractionation of Synthetic Polymers," H. L. Tung Ed., Marcel Dekker, New York, 1977 and H. Inagaki, Adv. Polym. Sci., 24, 189 (1977).

3. W. R. Moore and G. D. Edge, J. Polym. Sci., 47, 469 (1960).

4. see, for example, W. W. Scott in "Standard Methods of Chemical Analysis," Vol. 2, fifth ed, N. Howell Furman Ed., 1939, p 2485.

5. R. A. de Zeeuw in "Progress in Separation and Purification," Vol. 3, E. S. Perry, C. J. van Oss Ed., Wiley-Interscience, New York, 1970, p 1.

6. H. Inagaki, F. Kamiyama, and T. Yagi, Macromolecules, 4, 133 (1971).

7. H. Inagaki, T. Miyamoto, and F. Kamiyama, J. Polym. Sci., Polym. lett., 7, 329 (1969). 